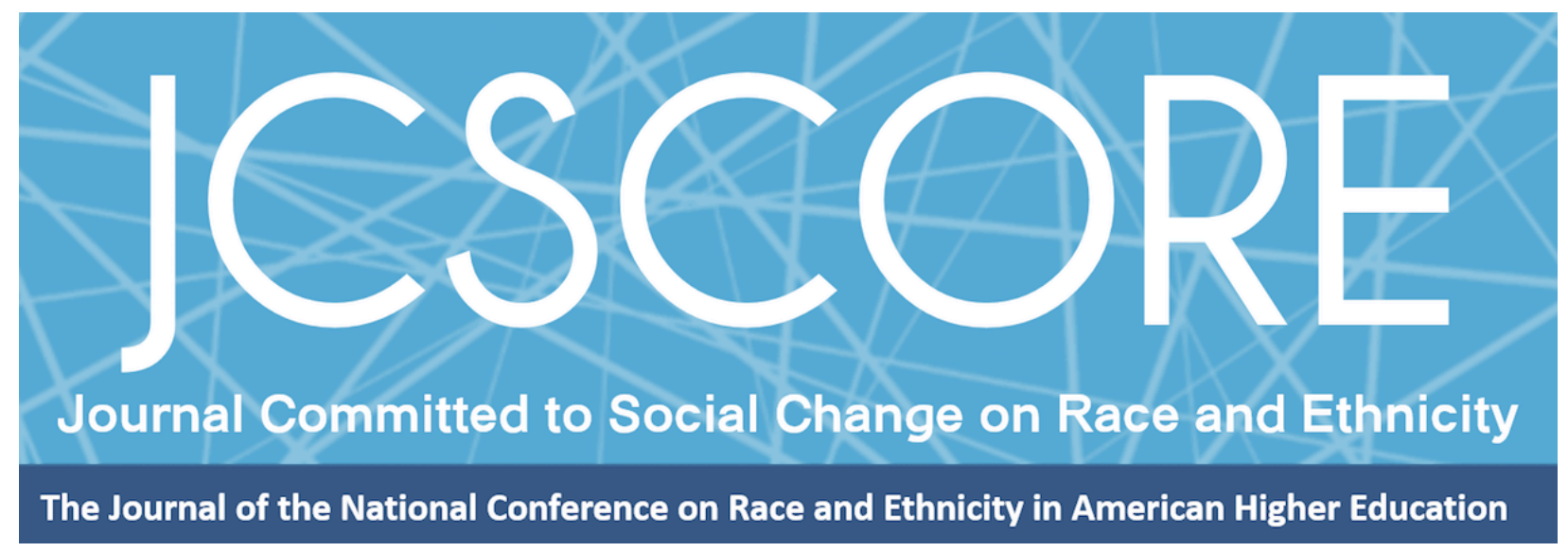

\title{
(EN)COUNTERING A WHITE RACIAL FRAME AT A \\ PREDOMINANTLY WHITE INSTITUTION: THE CASE OF THE AFRICAN AMERICAN STUDENT NETWORK
}

Tabitha Grier-Reed

University of Minnesota

Noah Gagner

University of Minnesota

Alex Ajayi

University of Minnesota

Journal Committed to Social Change on Race and Ethnicity

Volume 4, Issue 2 | 2018

Copyright $@ 2018$ Board of Regents of The University of Oklahoma on behalf of the Southwest Center for Human Relations Studies.

Permission of the Publisher is required for resale or distribution and for all derivative works, including compilations and translations. Quoting small sections of text is allowed as long as there is appropriate attribution. 


\title{
(EN)COUNTERING A WHITE RACIAL FRAME AT A PREDOMINANTLY WHITE INSTITUTION: THE CASE OF THE AFRICAN AMERICAN STUDENT NETWORK
}

\author{
Tabitha Grier-Reed \\ University of Minnesota \\ Noah Gagner \\ University of Minnesota \\ Alex Ajayi \\ University of Minnesota
}

\begin{abstract}
The White racial frame (WRF) is a set of cultural narratives and symbols based in White supremacy and anti-blackness that shape perceptions, ideologies, and emotions in U. S. society. The WRF also shapes individual experiences. Our research team explored how the WRF shaped experiences of Black college students. Adapting consensual qualitative research methods, we analyzed notes from discussions including 752 students participating in the African American Student Network (AFAM) over a twelve-year period. AFAM students encountered the WRF via inferior treatment and internalized racism including colorism, self-hate, and low expectations by educators and others. Colorism seemed especially relevant for women; encountering stereotypes of criminality seemed more prevalent for men. Students countered the WRF by finding safe/communal spaces, re-defining Blackness, re-examining Whiteness, and challenging stereotypes and racist epithets. (En)countering the WRF involved significant cognitive and emotional labor, and counterspaces that affirmed students' racial and cultural identities were essential for engaging in this work.
\end{abstract}

Black students at predominantly White institutions (PWI) of higher education often encounter hostile environments that denigrate People of Color and place inherent value in Whiteness. The inherent value that upholds Whiteness over others stems from a grand social narrative that Feagin (2013) called the White racial frame (WRF). The WRF is a set of cultural narratives and symbols based in White supremacy and antiblackness that shape perceptions, ideologies, and even emotions in U.S. society (Feagin, 2013). The WRF is thought to shape individual experiences, and we were 
interested in exploring how the WRF might shape the experiences of Black college students. To explore this question, we engaged in a case study using qualitative methods to analyze conversations in the African American Student Network (AFAM) between academic years $2005-06$ and $2016-17$. AFAM is an open networking group that meets weekly on a predominantly White campus in which Black students come together to find community and support as they discuss important issues in their lives.

Navigating a racial frame that places inherent value in Whiteness is considered an everyday occurrence for Americans (Feagin, 2013). Feagin (2013) conceptualized the WRF to include five components: stereotypes and prejudice; racialized narratives; racial images; racialized emotions; and, a tendency to discriminate against People of Color. Animalistic images of Black people as violent, criminal, unintelligent, lazy, and oversexed represent one of the conscious and unconscious anti-Black subframes of the WRF (Feagin, 2013). These images are often used to evoke thoughts of criminality and are connected with racialized emotions such as fear. Importantly, the stereotypes, narratives, racialized images, and emotions all function to advance a pro-White/antiother orientation that justifies discriminatory action in the United States.

Naming and understanding the WRF sets the stage for more fully observing, analyzing, and addressing the effects of racism in a way that takes into account its historical, structural, and institutional antecedents. Feagin (2013) argued that these antecedents are not fully accounted for by simply focusing on bias and prejudice which are primarily aimed at attitudes and beliefs. In contrast, the expansive scope of the WRF challenges the narrow view that bigots cause discrimination; that is, that individuals and/or small groups are the cause of discrimination in this country (Feagin, 
Journal Committed to Social Change on Race and Ethnicity | 2018

2013). Instead, the WRF draws attention to the longstanding, established nature of systemic racism across institutions in U. S. society that have justified chattel slavery of Black people and Jim Crow segregation along with The New Jim Crow of mass incarceration (Alexander, 2012).

In higher education the WRF is institutionalized and reified (Feagin, 2013). Gusa (2010) refers to this as White institutional presence (WIP). Gusa's (2010) conceptualization of WIP explains how the WRF is ingrained in PWIs via White ascendancy, White estrangement, White blindness, and monoculturalism. White ascendency promotes the superiority of the White race. One's status is considered hierarchical, and what is considered normal or the American dream is based on the position, views, values, and standards of those considered superior. Feagin (2013) outlines a number of attributes that are afforded to the status of being White, including: morality, intelligence, rationality, attractiveness, and the ability to work hard. For example, in the WRF, White is beautiful and Black is ugly. The standards imposed by this monocultural orientation result in pressures to assimilate and adjust to Whiteness in order to fit in and make oneself more acceptable or more attractive.

In institutions of higher education, Whiteness as the standard or WIP appears through a domination of discourse in classrooms via discussion time, textbooks, and special topics that relegate the histories and stories of People of Color invisible or marginal (Gusa, 2010). Furthermore, White blindness renders race and racial identities immaterial, and White estrangement maintains social and often physical distance between White students and Students of Color (Gusa, 2010). This estrangement is 
perpetuated through racialized emotions such as fear, contributing to the unwelcoming environment Black students experience at PWls.

There is a robust literature describing the chilly, hostile environments Black students experience on predominantly White campuses (Ancis, Sedlacek, \& Mohr, 2000; Davis et al., 2004; Gusa, 2010; Johnson et al., 2007; Park, 2009; Rankin \& Reason, 2005; Reid \& Radhakrishnan, 2003; Solorzano, Ceja, \& Yosso, 2000; Strayhorn, 2009; 2013; Watkins et al., 2007). Encounters with the WRF and WIP can be seen in these students' experiences of racism and inequitable treatment by faculty, staff, and teaching assistants, where Black students experience more racial conflict, pressure to conform to stereotypes, perceptions of discrimination, and prejudice than White students (Ancis et al., 2000; D'Augelli \& Hersberger, 1993; Davis et al., 2004; Sedlacek, 1983; Swim et al., 2003; Watkins et al., 2007). Stress related to acceptance or fitting in, coping, lack of social support, stigma, and hypervisibility/invisibility characterize these students' experiences (Davis et al., 2004; Watkins et al., 2007).

The importance of spaces that counter the WRF and validate People of Color have been highlighted in the literature (Feagin 2013; Solorzano et al., 2000). Such spaces allow Black students to become socially integrated into university life, to form relationships with other Black students and professionals, to seek support and mentorship, and to find respite from the WRF (Guiffrida \& Douthit, 2010). These "counterspaces" also provide a cultural home-base that validates Blackness and pushes back against oppressive narratives that shape students' collective realities (Feagin 2013; Grier-Reed, Madyun, \& Buckley, 2008). 
Journal Committed to Social Change on Race and Ethnicity | 2018

Our research focused on one such counterspace-the African American Student Network also known as AFAM. We were interested in how the WRF showed up in the everyday lives of students via their weekly discussions in AFAM. With implications for theory, research, and practice in antiracism work that furthers an understanding of how people may interpret and resist the WRF in everyday life, we adapted consensual qualitative research (CQR) methods to analyze notes from discussions in AFAM from 2005-06 to 2016-17.

\section{Methods}

This study was conducted with the approval of the Institutional Review Board at the participating university. To explore the question of how and whether the WRF showed up in the lives of students via their weekly conversations in AFAM, we engaged in an exploratory analysis of archival data, i.e., facilitators' notes of network discussions from 2005-06 to 2016-17. Between 2005-06 and 2016-17 there were a total of 324 AFAM meetings. The research team was able to obtain facilitators' notes from discussions at $250(77 \%)$ of those meetings; notes from 74 meetings were lost or missing. Each facilitator note was coded by the date of the meeting, and notes were taken either during or shortly after AFAM meetings. Graduate students who cofacilitated AFAM were assigned to take notes that captured the discussion each week. In turn, the archival data are based on facilitators' descriptions of what was discussed in AFAM. Graduate student co-facilitators turned their notes in to the principal investigator (PI) of this study who is also the co-founder of AFAM. The PI maintained AFAM data (e.g., notes and attendance records) in a secure location. 
Journal Committed to Social Change on Race and Ethnicity | 2018

Integrating theory, research, and practice, the PI worked with her research team to analyze how and whether the WRF could be applied to the archival data to contextualize the experiences and struggles captured in the AFAM discussions summarized by facilitators each week. The research team adapted the consensual qualitative research (CQR; Hill et al., 2005; Hill, Thompson, \& Williams, 1997) method to analyze the archival data for overarching themes and core ideas that connected to the WRF. CQR is a team-based qualitative research method. The research team in this study is composed of one African American woman and one African American man who co-facilitated the AFAM group. The African American woman is the PI of this study; born and raised in the Southern United States, she co-founded AFAM in 2005-06. The African American man is an advanced doctoral student in counseling psychology and an immigrant from Nigeria; he served as a co-facilitator of AFAM during the 2016-17 school year.

To begin the analysis, the PI worked independently to group similar content into initial research domains, and then submitted these data to her research team member for cross-analysis to determine whether the content in each domain seemed to fit together. After the cross-analysis, the team met to discuss and revise the initial domains and core ideas and to determine overarching themes. To counter tendencies toward groupthink, the researchers included an auditor. An advanced doctoral student in Family Social Science audited the preliminary results identified by the research team. The auditor was a biracial man identifying as Black and Alaskan Native; he co-facilitated AFAM during the 2017-18 school year. The audit resulted in six recommendations. Following the audit, the primary research team revised and shared results with the 
auditor. Once the auditor indicated that the team had effectively integrated feedback, the results were finalized.

\section{Participants}

Participants in AFAM were undergraduates across year in school (i.e., first-year, sophomore, junior, and senior), and many attended during multiple years of their education. Participants came from all over the University including but not limited to programs in biological sciences, education, liberal arts, business, agricultural and natural sciences, computer science, and engineering. In all, there were a total of 752 participants in the network from 2005-06 to $2016-17$ : $66 \%$ women, $29 \%$ men, and $5 \%$ did not report their gender. Students were native born African Americans as well as $1^{\text {st }}$ and $2^{\text {nd }}$ generation immigrants, with backgrounds including but not limited to Nigerian,

Liberian, Cameroonian, Somali, Kenyan, and Eritrean. Some participants also identified as biracial, multiracial, etc. Students attended an average of 8.5 AFAM meetings ( $S D=$ 12.8; range: $1-86 ;$ mode $=1$ ).

\section{Setting}

AFAM was developed at a PWI in the Midwest. This institution consists of 17 colleges (e.g., Liberal Arts, Education, Business). A large university, the institution has approximately 48,770 students, of which 29,352 are undergraduates. Within this institution, the gender composition is $46.7 \%$ men, $52 \%$ women, and $1.3 \%$ unknown. The racial and ethnic demographics are 0.3\% American Indian, 7.9\% Asian, 3.8\% African American/Black, 0.1\% Hawaiian, 3.5\% Hispanic, 12.5\% International, 3.2\% Multiracial, $64.6 \%$ White, and $4.1 \%$ unknown. 
Journal Committed to Social Change on Race and Ethnicity | 2018

AFAM is a counterspace designed to help Black students make meaning of their experiences at this PWI. Founded in 2005-06 by two Black university professors, AFAM is an open group for undergraduates that meets weekly over the lunch hour. Food is provided at each meeting, and students are able to come and go freely, i.e., students attend when they can and are not asked to attend a set number of meetings. Meetings in AFAM begin with introductions and check-ins, where students share a high and low moment from the week; then discussion is open for whatever students want to discuss. In other words, discussion is organic. There are no pre-formed agendas or curricula to follow.

Discussions in AFAM are co-facilitated by faculty and graduate students. These facilitators strive to meet students where they are, and conversations are facilitated using basic facilitation skills such as linking student stories, asking open-ended questions, and reflecting meaning. There were nine co-facilitators over the 12-year period of this study. Faculty co-facilitators included two African American men who were professors/instructors and one African American woman who was a professor at the PWI. Graduate student co-facilitators included two African American women, two African American men, and two biracial men who were graduate students at the PWI. Two of the students (one woman and one man) were master's level, and the rest were doctoral students.

An open and dynamic network, AFAM constantly takes in new people. The fact that the network began in 2005-06 and continues to this day is a testament to the sustained level of student engagement and interest in this counterspace. In fact, previous research has found that through AFAM students experienced safety, 
validation, connectedness, resilience, intellectual stimulation, empowerment, and a

home base on campus (Grier-Reed et al., 2008) and participation in the group seems to be therapeutic (Grier-Reed, 2013)—associated with positive social and academic outcomes (Grier-Reed \& Wilson, 2016; Grier-Reed, Ehlert, \& Dade, 2011; Grier-Reed, Arcinue, \& Inman, 2016).

\section{Results}

Approximately $80 \%$ (199) of the 250 notes we reviewed seemed connected to a WRF; the other $20 \%$ (51) were not, and are thereby excluded from the final results. The final results of this study are based on archival data from $60 \%$ of the 324 AFAM meetings that occurred over the 12-year period. However, dates for these archival data span the entire period of the study from 2005-06 to 2016-17 within (and across) each domain. Across the 199 facilitator notes we found evidence of White dominance or a WRF as well as ways students seemed to push back against it in discussions of everyday struggles. We also found evidence of the toll (en)countering a WRF had on

Table 1. Summary Results

\begin{tabular}{|l|l|}
\hline \multicolumn{1}{|c|}{ Domains } & \multicolumn{1}{c|}{ Themes } \\
\hline $\begin{array}{l}\text { Encountering the White Racial } \\
\text { Frame (WRF) in the transition } \\
\text { (from high school) to college }\end{array}$ & $\begin{array}{l}\text { In encountering White dominance and responding to the virtuousness of } \\
\text { Whiteness at a PWI, Black students were called upon to make adjustments } \\
\text { such as code-switching to fit into the White normative environment of the } \\
\text { education system and struggled with selling out, stereotypes, marginalization, } \\
\text { and racism. This included internalized racism and intragroup conflict, where } \\
\text { the WRF could also be encountered via negative attitudes held by Blacks } \\
\text { toward other Blacks. }\end{array}$ \\
\hline $\begin{array}{l}\text { Countering the White Racial } \\
\text { Frame (WRF) at a PWI }\end{array}$ & $\begin{array}{l}\text { In countering White dominance at a PWI, students questioned and/or pushed } \\
\text { back against denigration of Black people in functional and dysfunctional ways, } \\
\text { where functional ways included a focus on finding ways: to value Blackness } \\
\text { and Black culture, engage in social justice action, and find community, } \\
\text { especially at critical times, e.g., elections, campus closures, etc. Dysfunctional } \\
\text { ways included making excuses and protecting bad behavior when Black } \\
\text { people are perpetrators. }\end{array}$ \\
\hline $\begin{array}{l}\text { Cognitive and Emotional Labor } \\
\text { associated with the White } \\
\text { Racial Frame (WRF) at a PWI }\end{array}$ & $\begin{array}{l}\text { For Black students, the cognitive and emotional labor involved in navigating } \\
\text { the WRF at a PWI included anger, frustration, stress, exhaustion, and } \\
\text { resentment as a result of: hypervigilance, speaking out and } \\
\text { confronting/educating others; the racialized context of dating; and, developing } \\
\text { one's identity in the face of racial denigration. }\end{array}$ \\
\hline
\end{tabular}


students in the form of cognitive and emotional labor. Results are summarized in Table 1 and further discussed below.

\section{Encountering the WRF in the Transition (from High School) to College}

Discussions in AFAM included students sharing stories of being treated with low expectations by faculty, teachers, and even fellow students. Students shared stories of feeling racially profiled, and Black men discussed being criminalized even on campus. Students discussed how others generally viewed them as less intelligent, less capable, and less ambitious (e.g., not college material) and a sense that they had to prove themselves. Students in AFAM also talked about being treated differently from their White counterparts, where they felt that they generally received inferior treatment, support, and resources. See below for an excerpt from one AFAM discussion:

Then someone shared a story about an instance where they were asked to speak with high school students. The guidance counselor told the student that the second group was not really college bound, but they turned out to be very interested in college. This led to the question of how they as Black students were treated by teachers and guidance counselors in high school. Shared a number of stories about how they were treated with low expectations or experienced differential treatment from White folks.

Discussions in AFAM also revealed a sense that there seemed to be little room

for students' authentic Black selves in classes at their PWI, and they were called upon

to adapt and make adjustments in ways that they felt their White counterparts were not.

Students questioned the need to code switch and the pressure to act like someone they

were not in classes. See below for an excerpt from facilitator notes:

Then, the conversation moved on to the idea of code switching and students discussed how it seems like they need to develop a new language just for conversing with the dominant culture. For example, students talked about feigning interests in things because these are things they are supposed to like, 
usually based on White standards. Some students discussed frustration about what sometimes feels inauthentic, while others seemed to take the attitude of 'it is what it is, and you have to do what you need to do to make it'.

In addition, there were discussions of internalized racism, where Black students internalized low expectations for themselves. This extended to discussions of "colorism", e.g., lighter skin being associated with more privilege in the Black community: "One student initiated a discussion about the apparent animosity within the Black community as well as indices of self-hatred, the latter being related to the prevalence of skin bleaching and preference for White aesthetics." Moreover, students discussed stereotypes about Blacks held by other Blacks and the disconnect between Africans and African Americans. See below for two facilitator notes:

Student noticed that there are less African Americans. Stereotype among Africans is that African Americans don't value education. Discussion about how other groups value education. Do African Americans identify as Africans? What does it mean to be educated? Black history isn't taught in schools. There is a close association between Whiteness and education because Blackness is suppressed.

Talked about the disconnect for Black people embracing their 'Africaness'; How do you feel about being called African? Considered by some to be an insult. Talked about image of Africans not being positive. Primitive, barbaric were the images that came to mind. Started to accept 'African Pride'. Similar misconception/thoughts about view of African Americans from the African point of view. Comments about 'separating the people'. Africans vs. people who have been stripped of their history and culture (African Americans).

In conclusion White dominance and White ascendancy were apparent in conversations in AFAM as students discussed being treated as and/or viewing Blackness as inferior, less than, deviant, undesirable, and not belonging (e.g., not part of the curriculum, not college material). These encounters with a WRF based in White dominance and White ascendancy called on students to adjust, adapt, and even code switch. In student encounters with a WRF, stereotypes 
and racialized narratives about Blacks, such as animalistic images of Africans or perceptions of African Americans as not valuing education, could even be espoused by other Blacks.

\section{Countering the WRF at a PWI}

In AFAM countering the WRF seemed essential to maintaining a sense of integrity and authenticity. In the network students questioned and/or pushed back against the purported inferiority and denigration of Black people by finding community, valuing Blackness and Black culture, and engaging in social justice action, especially during critical times such as elections, campaigns to close diverse spaces on campus, and Black History Month. See below for two excerpts:

Discussion of how Black History month was being represented in their dorms. The students discussed how they would like to see Black History Month represented more openly on campus. They talked about the Hall Boards in their dorms not representing Black History Month and how this made them feel as though the dorms did not really care about them and their history. Several of the students discussed how they could change this by talking to the RAs in their dorms. Also they discussed how they could become more involved on campus so their concerns are more in focus.

Students then begin to discuss how they have taken stands and participated in activism. One student found out that MCAE [Multicultural Center for Academic Excellence] presentations were being cut during orientation for incoming freshman, and stopped this from happening. Another student organized a demonstration of Black men studying in the library on Friday. Another student talked about how he is sponsoring 12 AIDS orphans in Uganda and working with community and local government there. In the end, I noted the power in the community and inside the students, stating that they do not have to wait until they are older to make a difference. I encouraged them to start small, and see where that takes them.

In contrast to a WRF and WIP that marginalizes Blackness, students in AFAM discussed ways to more fully represent and promote the history, voices, experiences, and wellbeing of Black people. As one facilitator noted: "Finding ways to be inclusive but 
also support and protect exclusive Black spaces was a question of exploration as well as how to even have discussions around these sensitive issues." In these discussions, AFAM students underscored the importance of counterspaces; that is, spaces that counter deficit notions of People of Color.

This included re-examining Whiteness-broadening the discourse to discussions of "White fragility" and "White privilege"-and pushing back against "socially acceptable" uses of racial epithets such as the "N-word." See below for one example:

A student shared his experience in a class where a White student said the $\mathrm{N}$ word as part of her presentation. Students debated the appropriateness of White people using the word in an academic context. While it seems like most students thought that the word should not be used by White people under any circumstances, some students questioned the effectiveness of such language policing. Others discussed how it is impossible to control what people say in the luxury of their home. Students shared their experiences with White people using the word in their presence and how they handled it. Students noted the impact of having Black people vary on their permissiveness around other races using the word as some students shared examples of interacting with White people who say something like 'I have friends who let me say it.' The discussion then moved to the appropriateness of the use of the word among Black people, with a growing number of students sharing that Black people shouldn't be using the word either. Students discussed how hearing the word can be traumatic for some, even if the intent of the speaker is not malicious. Moreover, one noted...the implication of so many Black people being willing to use the word. Specifically, the student argued that White supremacy is what causes Black people to call themselves words that White people would call them to put them down.

Other ways of countering the WRF in AFAM included a tendency to explore or excuse rather than condemn bad behavior. For example, students questioned whether Michael Vick was punished too harshly for animal cruelty, highlighting a tension between holding other Blacks accountable for their actions and simultaneously refuting a WRF that casts Blacks as inherently bad or criminal. 
Students also re-examined what it means to be Black as indicated in the facilitator note below:

Group explored what it means to be Black. Conversation started with narrow definitions of Blackness. Questions of what makes someone less Black emerged. Students explored how far they could deviate from stereotypes without deviating from what it means to be Black. The question of does being educated make you less Black emerged. In the end students decided that there was nothing that could make you less Black except denying your sense of yourself as Black. Students then began to explore the pre-encounter stage of Cross' racial identity development model.

There was a sense that racism and a WRF that denigrates Blackness should not define students' sense of what it means to be Black. Again, the need for counterspaces, community, and positive connections with other Black people was identified as important. Students talked about the need for guidance, mentorship, community, and validation.

\section{Cognitive and Emotional Labor Associated with the WRF at a PWI}

(En)countering the WRF involved considerable cognitive and emotional labor.

This included the work of developing a healthy sense of identity and esteem along with other developmental tasks such as dating and finding love. For example, students in AFAM worked to find ways to affirm their Black identity within their life choices which led to pondering whether intimate relationships with other races (e.g., interracial dating) was a tacit endorsement of the WRF that places Blacks at the bottom in terms of attractiveness and desirability. See below for an excerpt from one discussion:

Then, they discussed the intersection of Black racial identity and partnering. Specifically, the theme was: Can you be pro-Black and engaging in interracial dating? There was disagreement in the room as some students suggested that it is difficult to be pro-Black and choose to commit long-term to someone who isn't Black. Moreover, others suggested that it might be difficult for partners from different racial backgrounds to fully understand one another. Others disagreed 
and suggested that perhaps exclusively dating outside of one's race may be problematic, but people can't choose who they fall in love with.

AFAM students grappled with a sense of limitations and/or freedom to date outside of their race while still affirming Blackness, i.e., remaining pro-Black.

Students felt a need to stand up or confront and educate others, speaking out against White dominance and the unjust nature of the WRF. See below:

The discussion turned to how to stand up for yourself and address ignorant comments without becoming a stereotype. Students shared different experiences and ways they have coped with these instances in the past, but struggled with ways to really address these racial incidents without shutting everyone down, getting angry, or going off.

How to stand up for oneself without becoming a stereotype was a source of puzzlement and frustration, as students experienced the "damned if you do, damned if you don't" dilemma described by Sue et al. (2007) in their discussion of racial microaggressions in everyday life. Racial microaggressions include the daily, commonplace assaults, insults, and invalidations that are just part of life for People of Color (Sue et al., 2007). Students in AFAM spent many meetings laboring over this dilemma and the best way to respond to these kinds of racial slights and racism. These discussions included an analysis of speaking out and the cost of speaking out.

Hypervigilance and cultural mistrust associated with existing within the WRF and WIP of their PWI were also substantial sources of cognitive and emotional labor. For example, students were highly sensitized to potential threats to diversity and inclusion at their institution. This included sensitivity regarding the attitudes of others and support for diversity in their environment. Moreover, students questioned whether their vigilance or sense of threat was warranted, i.e., whether their sense of cultural paranoia was "healthy." In 
summary, students in AFAM were expending energy due to the emotional demands of fear and hypervigilance and the cognitive demands of assessing whether they were overreacting (as is demonstrated in the facilitator note below):

After check-in conversation moved into a discussion of the defunding of BSU [the Black Student Union]. Many students hadn't heard about this. In turn, there were several questions about what happened as students tried to piece together a clear picture. Most all of the students in group admitted to using the BSU and felt that BSU was an essential part of their experience on campus. One student alluded to the belief that BSU was being targeted, particularly given the $2^{\text {nd }}$ Floor controversy last semester. However, she then questioned whether she was paranoid and discussed this feeling as just a part of her experience in daily life. In this discussion she talked about noticing that she was treated differently by peers in classes or in group work, where her thoughts or ideas often went unheard and/or invalidated. Others in group could relate to this experience. So, the group moved to a discussion of 'cultural paranoia' or healthy mistrust. Today, the group affirmed the idea of a healthy mistrust. I then asked students how they cope with questioning and wondering...the invalidations. Students had difficulty answering this question, but one suggested the importance of having cultural spaces where your own worldview and experience are validated. Again, the importance of having space like AFAM and BSU came up.

There was an emotional toll to the hypervigilance, sense of isolation or being the only one, and burden of speaking out or representing one's race on a campus that was less than $4 \%$ Black. The emotional undertow included feelings of anger, frustration, stress, exhaustion, and resentment.

Finally, protecting themselves from the negative effects of the hostile environment created by the WRF and WIP at their PWI was a source of cognitive and emotional labor. See below:

Other students discussed their own experiences with microaggressions in social settings and also discussed the toll of such indignities. They discussed conscious and unconscious decisions to avoid certain White spaces as a form of selfprotection. Students also discussed the role of race and [how] lived experiences shape their friendship choices. Some discussed having a fairly homogenous group of friends that tend to share their racial group membership. In particular, it 
seems that some thought it was more difficult to feel fully understood by White individuals.

Across the weekly discussions in AFAM, the importance of safe validating spaces, i.e., counterspaces, was a strong theme, particularly as students engaged in the cognitive and emotional labor of navigating/encountering, interpreting/making meaning of, and countering/resisting a WRF in their lives.

\section{Discussion}

We saw evidence of the WRF in $80 \%$ of the AFAM discussions summarized in the facilitators' notes that we analyzed. This represented $60 \%$ of AFAM meetings that occurred from 2005-06 to 2016-17. Evidence of the WRF in discussion notes spanned the entire period of the study from 2005-06 to 2016-17. The stereotype of Black people as unintelligent was a major way students experienced the WRF in this study. This racialized narrative of intellectual inferiority was prevalent in AFAM students' educational experiences.

Students discussed low expectations and feeling the need to prove themselves in educational settings. Similar experiences have been reported in the literature by scholars such as Strayhorn (2009) who found that even high achieving Black college students felt the pressure to prove themselves and demonstrate their intelligence and capabilities. Monoculturalism was another way students experienced the WRF, where the dominance of White standards and pressure to adjust or assimilate to these standards was evident in students feeling the need to code switch.

Encountering the ubiquitous WRF led to discussions of Black students internalizing low expectations for themselves. The internalization of White standards and preferences by Black people also seemed apparent in students' discussions of 
Journal Committed to Social Change on Race and Ethnicity | 2018

"colorism", "self-hate", and ethnic differences. For example, students discussed rifts between native born African Americans and recent African immigrants with each group viewing the other negatively and each group stereotyping the other using the racialized narratives and stereotypes found in the WRF, e.g., characterizing Blacks as uneducated, primitive, barbaric, etc.

Discussions of "colorism" seemed to reflect a gendered experience of the WRF associated with standards of beauty, where lighter skin is valued and considered more desirable than darker skin, i.e., the closer one is to White, the more desirable and attractive they are. Women in AFAM talked about the preference for White aesthetics and pressures to lighten their skin via skin bleaching. With men, the criminality aspect of the WRF prevailed. Men talked about being criminalized and racially profiled on and off campus; that is, the phenomenon of the "criminalblackman" coined by Kathryn Russell Brown (Alexander, 2012).

Encountering the racialized narratives for Black people associated with the WRF was part of students' daily and weekly experiences, but so was countering these narratives. Students pushed back against the WRF by valuing Blackness and Black culture. This included discussing ways to promote and celebrate Black history, redefine Blackness, and critically question "socially acceptable" use of racialized language that denigrates Black people. In the weekly discussions occurring in AFAM resistance to the WRF was less about grand gestures and more about small acts to assert one's dignity, worth, intelligence, and place in the world, e.g., talking to the Residential Advisors in the dorms about honoring Black history on the Hall Boards or organizing regular demonstrations of Black men studying in the library on campus. 
Journal Committed to Social Change on Race and Ethnicity | 2018

This included discussions of the best ways to stand up against and resist racist narratives without inadvertently feeding into them. Trying to discern how to confront racial microaggressions or White racism without looking like a stereotype was a strong theme in AFAM discussions and a major source of cognitive and emotional labor. Existing within the WRF took a toll on students. The hostile environment contributed to stress, resentment, frustration, and exhaustion. These findings align with research by D'Augelli and Hershberger (1993) who found that Black students at PWls tended to report poorer health and energy than their White counterparts. More recently, the accumulated stress of racism in these hostile environments has been linked to a number of negative outcomes for Black students (Conklin, 2011), including higher levels of psychological and physical health problems (Harper, 2009; Watkins et al., 2007).

\section{Implications}

Although the WRF was not at the heart of every AFAM discussion we analyzed, we did find it in $80 \%$ of our discussion notes (representing $60 \%$ of AFAM meetings over a 12-year period). These findings suggest that the WRF was a significant factor in students' lives and weekly discussions of everyday experiences, struggles, and preoccupations. Moreover, in these discussions, students underscored the need for counterspaces like AFAM to make meaning of their experiences and to validate their worldview.

Students seemed to use the space in AFAM to come together and unpack or interpret their encounters with the WRF, exploring the validity of navigational strategies such as code-switching for example. Moreover, students seemed to find in AFAM a community of resistance; that is, a setting that supported the resistance of racialized 
Journal Committed to Social Change on Race and Ethnicity | 2018

narratives that disparage Black people. In contrast to the WRF, in AFAM the Black experience was central rather than marginal and students could value and re-define Blackness in their own terms.

Case and Hunter (2012) identify counterspaces as settings that facilitate adaptive responding in coping with oppression primarily through interpretive narrative work, acts of resistance, and relational transactions. This is what we found in AFAM. By creating a support network facilitated by faculty and graduate students where Black undergraduates could make meaning of their experiences, we found that students in AFAM used the space to navigate, interpret, and resist the WRF. Moreover, Grier-Reed (2013) has identified AFAM as therapeutic, especially for coping with racial microaggressions (Grier-Reed, 2010). By naming, observing, and analyzing how the WRF appeared in discussions in AFAM, our research provides insight into one model for counteracting this dominant cultural narrative.

The AFAM model has been adapted and studied for students as young as high school. For example, Gbolo and Grier-Reed (2016) found that having AFAM groups for Black high school students resulted in experiences of safety, support, empowerment, affirmation, and connectedness in their school. Note this is in stark contrast to the experiences of denigration we uncovered in the current study when analyzing AFAM students' discussions of high school. Yet, the qualitative outcomes in Gbolo and GrierReed's (2016) AFAM groups are strikingly similar to those found for college students participating in AFAM (Grier-Reed et al., 2008).

Importantly, community, support, validation, and affirmation for Black students are particularly relevant for countering the WRF. Social support has been associated 
with the best potential outcomes for Blacks experiencing race-related stress (Utsey et al., 2000), and Black youth who talk to others about being treated unfairly tend to have higher grade point averages (Powell \& Jacob Arriola, 2003). This seems to bear out in AFAM, where Grier-Reed and Wilson (2016) found that AFAM students tended to have more social connections including more Black connections and more university connections than their counterparts and that AFAM students tended to have better academic outcomes (Grier-Reed et al., 2011; Grier-Reed et al., 2016).

Even though our research focused on African American students, counterspaces that support other People of Color are needed. The WRF is based in White ascendancy and monoculturalism (Feagin, 2013; Gusa, 2010); that is, the superiority of Whiteness and the inferiority of all others, where others are expected to assimilate or move toward Whiteness in order to become virtuous. The creation and study of more counterspaces that defy monoculturalism and deficit notions of People of Color and that affirm racial and cultural identities is vitally important.

\section{Limitations}

One limitation of our study is missing data; we were missing notes from $23 \%$ or 74 of the meetings that occurred from 2005-06 to 2016-17. The archival nature of our data may also be considered a limitation, where we relied on facilitators' notes or summaries of discussion rather than digital recordings or transcripts of discussions in AFAM. No such recordings or transcripts existed. Moreover, although we included member checking in the form of a cross analysis and an audit, we did not include a measure of testimonial validity in our research.

\section{Conclusion}


Integrating the theoretical perspective of the WRF with research on AFAM (an educational practice), our study illustrates ways in which this grand societal narrative showed up in the daily lives of Black students through organic conversations summarized by the co-facilitators of their weekly network meetings. The observation, documentation, and analysis of the WRF is essential to antiracism work that seeks to counter and upend it. Our research demonstrates the promise of counterspaces such as AFAM that provide community and support, where students in AFAM came together to question racialized narratives of White superiority through discussions of White privilege and to challenge notions of White ascendancy through discussions of White fragility. Most importantly, perhaps, students used the space in AFAM to counter pernicious racialized narratives for Black people—interpreting, redefining, and narrating Blackness in their own terms, finding ways to value Black culture and Black identity. 


\section{References}

Alexander, M. (2012). The new Jim Crow: Mass incarceration in the age of colorblindness. New York, NY: The New Press.

Ancis, J. R., Sedlacek, W. E., \& Mohr, J. J. (2000). Student perceptions of campus cultural climate by race. Journal of Counseling and Development, 78, 180-185.

Case, A. D., \& Hunter, C. D. (2012). Counterspaces: A unit of analysis for understanding the role of settings in marginalized individuals' adaptive responses to oppression. American Journal of Community Psychology, 50, 257-270.

Conklin, H. D. (2011). Perceived racism and mental health: A meta-analytic review. Doctoral dissertation retrieved from:

https://scholarsarchive.byu.edu/cgi/viewcontent.cgi?referer=https://www.google.c om/\&httpsredir=1\&article $=4034$ \&context $=$ etd

D'Augelli, A. R., \& Hershberger, S. L. (1993). African American undergraduates on a predominantly White campus: Academic factors, social networks, and campus climate. The Journal of Negro Education, 62, 67-81.

Davis, M., Dias-Bowie, Y., Greenberg, K., Klukken, G., Pollio, H. R., Thomas, S. P., \& Thompson, C. L. (2004). "A fly in the buttermilk": Descriptions of university life by successful Black undergraduate students at a predominantly White Southeastern university. The Journal of Higher Education, 75, 420-445.

Feagin, J. (2013). The White racial frame ( $2^{\text {nd }}$ ed). New York, NY: Routledge.

Gbolo, S., \& Grier-Reed, T. (April 1, 2016). An African American student networking group in an urban high school: Experiences and outcomes. Journal of Urban Education. Advance online publication.

Grier-Reed, T. (2013). The African American Student Network: An informal networking group as a therapeutic intervention for Black college students on a predominantly White campus. Journal of Black Psychology, 39, 169-184.

Grier-Reed, T. L. (2010). The African American Student Network: Creating sanctuaries and counter spaces for coping with racial microaggressions in higher education settings. Journal of Humanistic Counseling Education and Development, 49, 181-188.

Grier-Reed, T., Arcinue, F., \& Inman. E. (2016). The African American Student Network: An intervention for retention. Journal of College Student Retention: Research, Theory, \& Practice, 18, 183-193.doi: 10.1177/1521025115584747

Grier-Reed, T., Ehlert, J., \& Dade, S. (2011). Profiling the African American Student Network. The Learning Assistance Review, 16, 21-30.

Grier-Reed, T., Madyun, N., \& Buckley C. (2008). Low Black student retention on a predominantly White campus: Two faculty respond with the African American Student Network. Journal of College Student Development, 49, 476-485.

Grier-Reed, T., \& Wilson, R. J. (2016). The African American Student Network: An exploration of Black students' ego networks at a predominantly White institution. Journal of Black Psychology, 42, 374-386.

Guiffrida, D. A., \& Douthit, K. Z. (2010). The Black student experience at predominantly White colleges: Implications for school and college counselors. Journal of Counseling and Development, 88, 311-318.

Gusa, D. L. (2010). White institutional presence: The impact of Whiteness on campus climate. Harvard Educational Review, 80, 464-586. 
Harper, S. R. (2009). Niggers no more: A critical race counternarrative on Black male student achievement at predominantly White colleges and universities. International Journal of Qualitative Studies in Education, 22, 697-712.

Hill, C. E., Knox, S., Thompson, B. J., Williams, E. N., Hess, S. A., \& Ladany, N. (2005). Consensual qualitative research: An update. Journal of Counseling Psychology, 52, 196-205.

Hill, C. E., Thompson, B. J., \& Williams, E. N. (1997). A guide to conducting consensual qualitative research. The Counseling Psychologist, 25, 517-572.

Johnson, D. R., Alvarez, P., Longerbeam, S., Soldner, M., Inkelas, K. K., Leonard, J. B., \& Rowan-Kenyon, H. (2007). Examining sense of belonging among first-year undergraduates from different racial/ethnic groups. Journal of College Student Development, 48, 525-542. doi: 10.1353/cds.2007.0054

Park, J. J. (2009). Are we satisfied? A look at student satisfaction with diversity at traditionally White institutions. The Review of Higher Education, 32, 291-320.

Powell, C. L., \& Jacob Arriola, K. R. (2003). Relationship between psychosocial factors and academic achievement among African American students. Journal of Educational Research, 96, 175-181.

Rankin, S. R., \& Reason, R. D. (2005). Differing perceptions: How students of color and White students perceive campus climate for underrepresented groups. Journal of College Student Development, 46, 43-61.

Reid, L. D., \& Radhakrishnan, P. (2003). Race matters: The relation between race and general campus climate. Cultural Diversity and Ethnic Minority Psychology, 9, 263-275.

Sedlacek, W. E. (1983). Teaching minority students. In J. H. Cones, J. F. Noonan, \& D. Janha (Eds.), New directions for teaching and learning (pp. 39-50). San Francisco, CA: Jossey Bass.

Solorzano, D., Ceja, M., \& Yosso, T. (2000). Critical race theory, racial microaggressions, and campus racial climate: The experiences of AfricanAmerican college students. The Journal of Negro Education, 69, 60-73.

Strayhorn, T. (2013). Measuring race and gender differences in undergraduate students' perceptions of campus climate and intentions to leave college: An analysis in Black and White. Journal of Student Affairs Research and Practice, $50,115-132$.

Strayhorn, T. (2009). The burden of proof: A quantitative study of high-achieving Black collegians. Journal of African American Studies, 13, 375-387.

Sue, D. W., Capodilupo, C. M., Torino, G. C., Bucceri, J. M., Holder, A. M. B., Nadal, K. L., \& Esquilin, M. (2007). Racial microaggressions in everyday life: Implications for clinical practice. American Psychologist, 62, 271-286. doi: 10.1037/0003066X.62.4.271

Swim, J. K., Hyers, L. L., Cohen, L. L., Fitzgerald, D. C., \& Bylsma, W. H. (2003). African American college students' experiences with everyday racism: Characteristics and responses to these incidents. Journal of Black Psychology, 29, 38-76.

Utsey, S. O., Ponterotto, J. G., Reynolds, A. L., \& Cancelli, A. A. (2000). Racial discrimination, coping, life satisfaction, and self-esteem among African Americans. Journal of Counseling and Development, 78, 72-80. 
Journal Committed to Social Change on Race and Ethnicity | 2018

Watkins, D. C., Green, B. L., Goodson, P., Guidry, J., \& Stanley, C. (2007). Using focus groups to explore the stressful life events of Black college men. Journal of College Student Development, 48, 105-118. 